\title{
Comparison of Laparoscopic TAPP (Transabdominal Preperitoneal) and Laparoscopic TEP (Totally Extra peritoneal) Techniques for Inguinal Hernia Repair- An Observational Study of 60 Cases
}

\author{
Dr. Milind P. More ${ }^{1}$, Dr. Amrit Manik Nasta ${ }^{2}$, Dr. Rakhi M. More ${ }^{3}$, \\ Dr. Rakesh Shedge ${ }^{4}$ \\ ${ }^{1}$ Associate Professor, Department Of Surgery, Seth G.S. Medical College \& K.E.M.H., Parel, Mumbai. India. \\ ${ }^{2}$ Senior Registrar, Department Of General Surgery, Seth G.S. Medical College, Mumbai, India. \\ ${ }^{3}$ Associate Professor, Department Of Anatomy, K.J.Somaiya Medical College \& Research Centre, Somaiya \\ Ayur Vihar, Everard Nagar, Sion, Mumbai 22, India. \\ ${ }^{4}$ Assistant Professor, Department Of Pathology, T.N.Medical College \& Nair Hospital, Mumbai Central \\ Mumbai, India.
}

\begin{abstract}
:
Introduction: In the last two decades there has been an increased use of laparoscopic inguinal hernia repair compared to open hernia repair. Laparoscopic techniques have been validated as safe and effective in the treatment of groin hernias and have become common where facilities are available. There has been a shift in the last few years from open repair to laparoscopic repair in India. The laparoscopic approach (TEP and TAPP) for inguinal hernia is bound to get more accessible in the near future.

Aims and Objectives: The purpose of this study was to compare laparoscopic TAPP (Transabdominal preperitoneal) and laparoscopic TEP (Totally extraperitoneal) repairs for inguinal hernia.

Materials and Methodology: This retrospective observational study was conducted in a tertiary care centre from November 2014 to November 2015. It consisted of 60 operated cases of inguinal hernia distributed 30 each in two groups i.e. Group A (TEP) and Group B (TAPP). After taking informed consent, patient details with respect to the study was entered on case record form. Each patient was followed up post-operatively for a period of 3 months. Statistical tests of significance were applied on various intra-operative and post-operative parameters to be compared between the two techniques.

Results: The mean duration of surgery by TEP technique was comparatively less than the TAPP technique. The intraoperative bleeding was minimal in cases of those operated by TEP as well as those operated by TAPP. There was no incidence of intraoperative bowel injury in our study in both groups. There was no incidence of intraoperative nerve injury in both groups. There was no difference in intraoperative conversion to open repair rates between TEP and TAPP. Seroma formation in the postoperative period was significant in TEP technique operated patients. There was no evidence of significant cord edema in the early postoperative phase of TEP and TAPP. The postoperative pain was more in TAPP as compared to TEP. There was no incidence of wound infection in TEP and TAPP. There was no difference in duration of hospital stay in TEP and TAPP. There was no difference in cost for surgery between TEP and TAPP. There was no incidence of recurrence of inguinal hernia in TEP as well as TAPP in early post-operative period. There was no difference in patient satisfaction in both the techniques.

Keywords: Inguinal hernia, TAPP (Transabdominal preperitoneal), TEP (Totally extraperitoneal)
\end{abstract}

\section{Introduction}

Hernia is derived from the Latin word for "rupture". A hernia is defined as an abnormal protrusion of an organ or tissue through a defect in its surrounding walls (1). The first evidence of operative repair of a groin hernia dates back to the first century AD. Bassini revolutionized the surgical repair of the groin hernia with his novel anatomical dissection and low recurrence rates of hernia. The advances in groin hernia repair in the century following Bassini have shared the primary objective of reducing long-term hernia recurrence rates. Darn repairs were first introduced in the early 20th century to reduce wound tension by using either autologous tissue or synthetic suture to bridge the gap between tissues. In 1918, Handley introduced the first use of silk as a prosthetic darn and nylon followed several years later. The first patches, beginning in the early 20th century, consisted of silver wire filigree sheets that were placed along the inguinal canal. The modern synthetic patch, made of a plastic monofilament polymer (polyethylene), was introduced by Usher in 1958 (1). Today, laparoscopic techniques have been validated as safe and effective in the treatment of groin hernias and have become common. The laparoscopic approaches were initially developed in the early 1990s as laparoscopic

DOI: $10.9790 / 0853-150729093$

www.iosrjournals.org

90| Page 
techniques diffused throughout other specialties of general surgery. In the last two decades there has been increased use of laparoscopic inguinal hernia repair compared to open hernia repair (1). The major dilemma is the technique of choice to proceed laparoscopically. There are three methods for laparoscopic methods of inguinal hernia repair. They are:

- Totally extraperitoneal (TEP) repair

- Transabdominal preperitoneal (TAPP) repair

- Intra peritoneal only mesh (IPOM) repair

Out of the above three methods the IPOM repair has largely been abandoned due to increased risk of nerve injury, organ injury and recurrence and the most common laparoscopic repairs are TEP or TAPP (2).

\section{Aims And Objectives}

1. To compare operative time, conversion rates and intra-operative complications of laparoscopic TEP and TAPP techniques of inguinal hernia repair.

2. To compare post-operative complications of the two techniques.

\section{Materials And Methodology}

This observational study was conducted in a tertiary care centre from November 2014 to November 2015. It consisted of 60 operated cases of inguinal hernia distributed 30 each in two groups i.e. GROUP A(TEP) and GROUP B (TAPP).

Patients in both the groups were assessed for the following parameters:

1. Conversion rates to open method

2. Procedure time

3. Intra operative complications- bleeding, bowel and nerve injury

4. Post operative pain

5. Post operative complications- seroma, cord edema, pain and surgical site infection

6. Duration of stay in hospital

7. Early recurrence rates

8. Cost effectiveness

9. Patient satisfaction

\section{Selection of the Subjects:-}

Inclusion criteria:

1) Patients diagnosed as having inguinal hernia aged 18 years and above giving valid written informed consent

2) Patients with unilateral or bilateral inguinal hernia

3) Patients with recurrent inguinal hernia.

\section{Exclusion criteria:}

1) Patients with complicated inguinal hernia

2) Patients with failed laparoscopic repair of inguinal hernia

3) Patients deemed unfit for general anaesthesia

\section{Methodology:}

We undertook an observational study during the above mentioned period. All cases procured had undergone laparoscopic TEP or TAPP repair by the standard techniques, using Polypropylene mesh $15 \mathrm{x} 15 \mathrm{~cm}$ in size for the involved side, mesh was not fixed in either technique. In TAPP technique, the peritoneum was sutured using Vicryl 3-0 by continuous technique. After taking informed consent patient details with respect to the study, data was entered on case record form. Patients were examined daily during their admission and on follow up on day 7, 14, 30 and 90. The data was entered on masterchart in excel spreadsheet and further statistical analysis was done using measures of central tendencies and various tests of significance.

\section{Results}

In our study, in both the groups, i.e Group A (TEP) and Group B (TAPP), all patients were males. The mean age of the patients in Group A was $36.27 \pm 1.692, n=30$ and the mean age of the patients in Group B was $33.60 \pm 1.323, n=30$. Hence, there was no significance between the two groups for age of the patients (Table 1).

In Group A there were 22 cases of indirect inguinal hernia and 8 cases of direct inguinal hernia. While in Group B there were 25 cases of indirect inguinal hernia and 5 cases of direct inguinal hernia. In Group A there were 22 cases of right sided hernia, 4 cases of left sided hernia and 4 cases of bilateral inguinal hernia. In Group B there were 21 cases of right sided hernia, 6 cases of left sided hernia and 3 cases of bilateral inguinal hernia (Table 1). In Group A the mean duration of surgery was $50.50 \pm(\mathrm{SD}) 3.763$,(in minutes). In Group B the 
mean duration of surgery was $121.0 \pm$ (SD) 4.324 (in minutes). Using unpaired t test for statistical analysis the p- value was found to be $<0.0001$ which is statistically significant. In both the groups there was no significant bleeding intra-operatively. There was no incidence of bowel injury in any patient of the two study groups. There was no incidence of nerve injury during dissection in any of the two study groups. In Group A, there was one case in which the laparoscopic technique was converted to open (Lichtenstein tension-free meshplasty) technique due to difficulty in dissection intraoperatively. In Group B, there was no incidence of conversion to open technique for inguinal hernia repair and all the patients were operated laparoscopically in this group.

There is no significant difference between the two techniques in relation to postoperative seroma formation. In Group A, there was no patient in whom cord edema was present in immediate post operative phase. In Group B, there was 1 patient in whom cord edema was present in immediate post operative phase which was managed conservatively with athletic scrotal support. Visual Analogue scale was used for the study with pain scores ranging from (10 -100) with higher scores depicting better state of health and more comfort. The average pain score for Group A patients in immediate postoperative phase was $71.67 \pm 1.596$. The average pain score for Group B patients in immediate postoperative phase was $57.67 \pm 1.899$. Using unpaired test for statistical analysis the p- value was found to be $<0.0001$ which is statistically significant. Hence, patients in Group A had less postoperative pain than those in Group B. There were no cases of wound infection in both the groups. There is no significant difference between the two groups with relation to hospital stay. The patients in both the groups followed up on 7th day, 14th day, 1 month and at 3 months postoperatively. During these visits the patients in both the groups were assessed for seroma formation, cord edema, and recurrence of hernia. At 7 th day post op, seroma was found in 6 patients in group A while there were no cases of seroma in group B patients. Hence, there is significant difference in rates of postoperative seroma formation in both the groups. At 7 th day post op, cord edema was found in 1 patient in group A and none in group B. In group A \& B, there were no recurrences of inguinal hernia recorded in postoperative follow up. The patient's satisfaction for the hernia surgery was recorded at the 3rd month postoperatively. The grades of satisfaction were graded as satisfactory, good and excellent and on a verbal rating scale of 1 to 3. In Group A, 3 patients graded the surgery as satisfactory, 22 patients graded it as good and 5 patients graded it as excellent. In Group B, 6 patients graded the surgery as satisfactory, 23 patients graded it as good and 1 patient graded it as excellent.

\section{Discussion}

In our study, all the patients in Group A and Group B were males. The incidence of inguinal hernia in males compared to females is 7:1 (3). In our study, the Group A (TEP) the mean age of patient was 36.2 while the mean age of Group B(TAPP) patient was 33.6. This result was similar to study done by Rutkow et al that the incidence of hernia is higher in middle age adults (4). In our study, in both the groups $70 \%$ patients had right sided hernia while $20 \%$ had a left sided hernia and $10 \%$ patients had bilateral inguinal hernia. This result were similar to the study performed by Katz et al(3) who reported about $70 \%$ right sided hernia while bilateral hernias were $10 \%$. The operative time in our study was less in TEP technique as compared to TAPP technique. This result was similar to study by Wake et al and Asuri K et al that showed that operative time was higher in TAPP technique due to time taken for suturing the peritoneum covering the mesh(5). In our study, both the group had minimal intraoperative bleeding. Tamme $\mathrm{C}$ et al (6) studied TEP technique and concluded in their study that there was no intraoperative vascular injury reported. Similarly, Leibl et al studied TAPP technique and reported no vascular injury (7). There was no bowel injury reported in our study in either Group A nor there was any incidence of bowel injury in Group B patients. Studies by Khoury et al have shown incidence of bowel injuries of about $0-0.06 \%$ in laparoscopic hernia repair. (8) Thus risk of bowel injury is minimal in laparoscopic hernia repair. There was one $(3 \%)$ reported case of conversion to open repair in Group A while there were no conversions to open repair in Group B patients in our study. This results were similar to a study by Khoury et al that showed a increased incidence of conversion to open repair in TEP technique with a conversion rate of 0 7\%.(8) In our study we found that those operated by TEP were far more comfortable and pain was less $\{71.67$ $\pm(\mathrm{SD}) 1.596,(\mathrm{n}=30)\}$ than those operated by TAPP $\{57.67 \pm(\mathrm{SD}) 1.899\}$. The difference was found to be significant ( $\mathrm{p}$ value $<0.0001$ ). Asuri $\mathrm{k}$ et al found that postoperative pain in those operated by TEP was less than those operated by TAPP $\mathrm{p}=0.007$ (9). Our results were similar to this study proving that TEP has less postoperative pain than those operated by TAPP. In our study, there was 1 case $(n=1)$ of cord edema in Group A $(3.33 \%)$ as well as in Group B $(n=1)$ in the first follow up visit i.e 7th day postop. The difference was not significant between the two techniques. ( $p$ value $=1.5085$ ). The incidence of cord edema in our study was much less than the study done by Asuri k et al (9)and Shultz et al (10) who showed higher incidence of cord edema in the immediate postoperative phase. The incidence of recurrence following TEP repair has been found to be 0.6$1 \%(6)$, while the recurrence rate for TAPP has been around $0-3 \%$ (11). However, in our study there was no recurrence in any of the patients in the immediate postoperative period or in any of the follow up visits $(0 \%)$ upto 3 months postoperatively. 


\section{Conclusion}

1) The Operative Time Is Less In TEP Technique As Compared To TAPP Technique.

2) TEP Technique Operated Patients Had Less Postoperative Pain than Those Operated By TAPP Technique

3) Seroma Formation Was Significantly Higher In TEP Operated Patients.

4) The Recurrence Rates Were Similar In Both TEP And TAPP Techniques In Early Post Operative Period.

\section{References}

[1]. Read RC, Herniology: past, present, and future, Hernia, 13(6), 2009, 577-580.

[2]. McCormack K, Scott NW, Go PM, Ross S, Grant AM. Laparoscopic techniques versus open techniques for inguinal hernia repair. Cochrane database Syst Rev.2003 Jan ; (1):CD001785.

[3]. Katz DA. Evaluation and management of inguinal and umbilical hernias. Pediatr Ann. 2001 Dec; 30(12):729-35.

[4]. Rutkow IM. Epidemiologic, economic, and sociologic aspects of hernia surgery in the United States in the 1990s. Surg Clin North Am. 1998 Dec; 78(6):941-51.

[5]. McCormack K, Wake BL, Fraser C, Vale L, Perez J, Grant A. Transabdominal pre- peritoneal (TAPP) versus totally extraperitoneal (TEP) laparoscopic techniques for inguinal hernia repair: a systematic review. Hernia. 2005 May; 9(2):109-14.

[6]. Tamme C, Scheidbach H, Hampe C, Schneider C, Köckerling F. Totally extraperitoneal endoscopic inguinal hernia repair (TEP). Surg Endosc. 2003 Feb;17(2):190-5.

[7]. Bittner R, Schmedt C-G, Schwarz J, Kraft K, Leibl BJ. Laparoscopic transperitoneal procedure for routine repair of groin hernia. Br J Surg. 2002 Aug; 89(8):1062-6.

[8]. Khoury N. A comparative study of laparoscopic extraperitoneal and transabdominal preperitoneal herniorrhaphy. J Laparoendosc Surg. 1995 Dec; 5(6):349-55.

[9]. Krishna A, Misra MC, Bansal VK, Kumar S, Rajeshwari S, Chabra A. Laparoscopic inguinal hernia repair: transabdominal preperitoneal (TAPP) versus totally extraperitoneal (TEP) approach: a prospective randomized controlled trial. Surg Endosc. 2012 Mar; 26(3):639-49.

[10]. Schultz C, Baca I, Götzen V. Laparoscopic inguinal hernia repair. Surg Endosc. 2001 June; 15(6):582-4.

[11]. Birth M, Friedman RL, Melullis M, Weiser HF. Laparoscopic transabdominal preperitoneal hernioplasty: results of 1000 consecutive cases. J Laparoendosc Surg. 1996 Oct; 6(5):293-300.

\section{TABLES}

1. Age, type and laterality of hernia distribution in the TEP and TAPP groups

\begin{tabular}{|l|l|l|l|}
\hline & TEP group & TAPP group & $\begin{array}{l}\text { P value using unpaired } \\
\text { t test/ Fishers exact test }\end{array}$ \\
\hline Mean Age & $36.27+/-1.69$ years & $33.60+/-1.323$ years & 0.219 \\
\hline $\begin{array}{l}\text { Types of hernia } \\
\text { a) Direct }\end{array}$ & 8 & 5 & 0.521 \\
\hline B) Indirect & 22 & 25 & \\
\hline $\begin{array}{l}\text { Laterality } \\
\text { a) Unilateral }\end{array}$ & 26 & 27 & 0.902 \\
\hline b) Bilateral & 4 & 3 & \\
\hline
\end{tabular}

2. Comparison of intra-operative and post-operative parameters in TEP and TAPP groups

\begin{tabular}{|l|l|l|l|}
\hline Parameters & $\begin{array}{l}\text { TEP group } \\
(\mathrm{n}=30)\end{array}$ & $\begin{array}{l}\text { TAPP group } \\
(\mathrm{n}=30)\end{array}$ & $\begin{array}{l}\mathrm{P} \text { value using unpaired } \\
\mathrm{t} \text { test/ Fishers exact } \\
\text { test }\end{array}$ \\
\hline Duration of surgery & $\begin{array}{l}50.50+/ \text { - (S.D.) } 3.763 \\
\text { minutes }\end{array}$ & $\begin{array}{l}121.0+/-(\text { S.D. }) 4.324 \\
\text { minutes }\end{array}$ & $<0.0001$ \\
\hline $\begin{array}{l}\text { Intra-operative } \\
\text { bleeding, bowel or } \\
\text { nerve injury }\end{array}$ & 0 & 0 & 1 \\
\hline Conversion to open & $1 / 30$ & $0 / 30$ & 1 \\
\hline $\begin{array}{l}\text { Post-operative } \\
\text { seroma formation }\end{array}$ & $6 / 30$ & $0 / 30$ & 0.024 \\
\hline Cord edema pain & $1 / 30$ & $1 / 30$ & 1.508 \\
\hline $\begin{array}{l}\text { Postoperative } \\
\text { score (10 to 100) }\end{array}$ & $71.67+/$ - (S.D.) 1.596 & $57.67+/$ - (S.D.) 1.899 & $<0.0001$ \\
\hline Hospital stay a post- & $2.0+/-0$ days & $2.10+/-0.055$ days & 0.083 \\
\hline $\begin{array}{l}\text { Recurrence at } \\
\text { operative day 90 }\end{array}$ & 0 & 1 \\
\hline
\end{tabular}

